\title{
13 Years of TOPEX/POSEIDON Precision Orbit Determination and the 10-fold improvement in expected orbit accuracy
}

F.G. Lemoine, Space Geodesy Laboratory, NASA GSFC, Greenbelt, Maryland 20771 USA (Frank.Lemoine@gsfc.nasa.gov), N.P Zelensky, SGT Inc, Greenbelt, Maryland USA (nzelensky@sgt-inc.com), S.B. Luthcke, Space Geodesy Laboratory, NASA GSFC, Greenbelt, Maryland 20771 USA (Scott.B.Luthcke@nasa.gov), D.D. Rowlands, Space Geodesy Laboratory, NASA GSFC, Greenbelt, Maryland 20771 USA (drowland@bowie.gsfc.nasa.gov), D.S. Chinn, SGT Inc, Greenbelt, Maryland USA (dchinn@bowie.gsfc.nasa.gov), B.D. Beckley, SGT Inc, Greenbelt, Maryland USA (brianb@nemo.gsfc.nasa.gov), S.M. Klosko, SGT Inc, Greenbelt, Maryland USA (sklosko@sgt-inc.com)

\begin{abstract}
Launched in the summer of 1992, TOPEX/POSEIDON (T/P) was a joint mission between NASA and the Centre National d'Etudes Spatiales (CNES), the French Space Agency, to make precise radar altimeter measurements of the ocean surface. After the remarkably successful 13-years of mapping the ocean surface $T / P$ lost its ability to maneuver and was de-commissioned January 2006. T/P revolutionized the study of the Earth's oceans by vastly exceeding pre-launch rstimates of surface height accuracy recoverable from radar altimeter measurements. The precision orbit lies at the heart of the altimeter measurement providing the reference frame from which the radar altimeter measurements are made. The expected quality of orbit knowledge had limited the measurement accuracy expectations of past altimeter missions, and still remains a major component in the error budget of all altimeter missions. This paper describes critical improvements made to the T/P orbit time series over the 13-years of precise orbit determination (POD) provided by the GSFC Space Geodesy Laboratory. The POD improvements from the pre-launch T/P expectation of radial orbit accuracy and Mission requirement of 13-cm to an expected accuracy of about 1.5-cm with today's latest orbits will be discussed. The latest orbits with $1.5 \mathrm{~cm}$ RMS radial accuracy represent a significant improvement to the $2.0-\mathrm{cm}$ accuracy orbits currently available on the T/P Geophysical Data Record (GDR) altimeter product.
\end{abstract}

\section{Introduction}

At the time of launch in 1992, the T/P altimeter mission had one of the most stringent orbit determination requirements ever imposed on a satellite mission $13 \mathrm{~cm}$ RMS (1- $\sigma$ ) radial accuracy. In 1992 this estimate was considered somewhat optimistic and was based on the successful advances in gravity field modeling and anticipated improvements with gravity field tuning, anticipated improvements in modeling the satellite surface forces, and the anticipated strength of the Satellite Laser Ranging (SLR) and DORIS Doppler measurements 
tracking T/P (Nerem et al., 1993). Following launch, the pre-launch orbit accuracy estimates proved to be wrong in that they under-estimated the degree of success achieved improving the POD models, and especially the gravity field (Tapely et al., 1994). The initial first generation orbits, based on the JGM-2 gravity field, had achieved the unprecedented radial accuracy of 3-4 cm (Tapely et al., 1994). In 1995 significant improvements in the gravity and tide models, reference frame definition and tracking station positions, and surface force modeling led to the adaptation of new POD standards, and the second generation, JGM-3 gravity based orbits. These orbits achieved $2.0-2.5 \mathrm{~cm}$ accuracy (Marshall et al., 1995), and were used for all of the GDRs. The orbits were computed at the GSFC Space Geodesy Laboratory based on SLR/DORIS tracking. In 2002, with the adoption of the ITRF2000 station coordinates (Altamimi et al., 2002) it became evident the T/P SLR/DORIS orbits could be further improved with the application of the reduced-dynamic technique and other POD strategy improvements (Luthcke et al., 2003). In 2005 the Grace-derived GGM02C gravity field (Tapley et al., 2005) offered significant additional advantage over the JGM-3 field. Using these and other recent POD model improvements, the latest T/P SLR/DORIS orbits are computed with an estimated radial accuracy of $1.5 \mathrm{~cm}$. Currently the refinement and testing of certain models, such as the time-varying gravity field is still ongoing, but when that is completed the GSFC Space Geodesy Laboratory plans to reprocess the entire time series of T/P orbits using the best models.

\section{POD Analysis}

The T/P satellite flies in a nearly circular orbit at an average of $1335 \mathrm{~km}$ with an inclination of $66^{\circ}$. It has a period of 112.4 minutes and a ground-track repeat cycle of 9.92 days after completing 127 orbital revolutions. T/P contains four tracking systems which can be used for precision orbit determination:

1) SLR

2) DORIS

3) Global Positioning System (GPS)

4) the satellite altimeter measurements themselves which can be used as a supplementary type

With AS on unfortunately only one frequency can be used with the GPS Monarch receiver limiting the GPS POD capability to about 1-year for T/P when AS was turned off. This work relies on the processing and analysis of SLR, DORIS, and altimeter crossover data. Although there is no measure of absolute orbit accuracy, an ensemble of tests including data residual analysis, orbit consistency between overlapping data periods, and direct orbit comparison have been used to evaluate 1-cm accuracies (Lutchke et al., 2003), and are used in this study. Improvement of the T/P orbit has led to improved consistency between the T/P and Jason-1 (T/P follow-on mission) datasets and can be used as an additional measure of improved T/P orbit accuracy (Beckley et al., 2004).

\section{Summary}

This paper describes the history of improvements to T/P orbit accuracy, presents current additional improvements and discusses possible future improvements to 
T/P POD. The POD methodology is presented and improvements to the gravity, tide, surface force, and other models are described. The orbit error is characterized and presented for significant stages in improved POD modeling. Table 1. below offers a summary of tracking data residuals computed over cycles 344-364, and illustrates the relative improvement of the computed orbit with improved POD models and strategies. The altimeter crossovers are not used in the orbit solution and therefore offer an independent measure of radial orbit accuracy.

Table 1. T/P orbit performance cycles 344-364

\begin{tabular}{|l|c|c|c|}
\hline \multirow{2}{*}{ Orbit (SLR/DORIS) } & \multicolumn{3}{|c|}{ RMS residuals } \\
\cline { 2 - 4 } & $\begin{array}{c}\text { DORIS } \\
(\mathrm{mm} / \mathrm{s})\end{array}$ & $\begin{array}{c}\text { SLR } \\
(\mathrm{cm})\end{array}$ & $\begin{array}{c}\text { Crossover } \\
(\mathrm{cm})\end{array}$ \\
\hline $\begin{array}{l}\text { GDR } \\
\text { dynamic, JGM3, CSR95 stations }\end{array}$ & 0.467 & 2.522 & 5.618 \\
\hline $\begin{array}{l}\text { dynamic } \\
\text { dynamic, JGM3, ITRF2000 }\end{array}$ & 0.467 & 2.024 & 5.564 \\
\hline $\begin{array}{l}\text { reduced-dynamic } \\
\text { reduced- dynamic, JGM3, ITRF2000 }\end{array}$ & 0.465 & 1.979 & 5.545 \\
\hline $\begin{array}{l}\text { ggm02c_red } \\
\text { reduced-dynamic, GGM02C, ITRF2000 }\end{array}$ & 0.464 & 1.873 & 5.496 \\
\hline
\end{tabular}

\section{References}

Altamimi Z, P Sillard and C Boucher (2002), ITRF2000: A new release of the International Terrrestrial Reference Frame for earth science applications, J. Geophys. Res., 107(B10): 2214, DOI:10.1029/2001JB000561.

Beckley, BD, NP Zelensky, SB Luthcke, and PS Callahan (2004), Towards a seamless transition from TOPEX/POSEIDON to Jason-1, Marine Geodesy, 27(3-4): 373-389, 2004.

Luthcke, SB, NP Zelensky, DD Rowlands, FG. Lemoine, TA. Williams (2003). The 1-centimeter orbit: Jason-1 precision orbit determination using GPS, SLR, DORIS and Altimeter data, Marine Geodesy, 26(3-4): 399-421.

Marshall, JA, NP Zelensky, SB Luthcke, KE Rachlin, and RG Williamson (1995), The temporal and spatial characteristics of TOPEX/Poseidon radial orbit error, J. Geophys. Res, 100(C12): 25331-25352.

Nerem, RS, BH Putney, JA Marshall, FJ Lerch, EC Pavlis, SM Klosko,SB Luthcke, GB Patel, RG Williamson, and NP Zelensky (1993) Expected orbit determination performance for the TOPEX/POSEIDON Mission, IEEE Trans. Geosci. Remote Sens., 31(2), 1993. 
Tapley BD, JC Ries, GW Davis, RJ Eanes, BE Schutz, CK Shum, MM Watkins, JA Marshall, RS Nerem, BH Putney, SM Klosko, SB Luthcke, D Pavlis, RG Williamson and NP Zelensky (1994), Precision Orbit Determination for TOPEX/POSEIDON, J. Geophys. Res, 99(C12): 24383-24404.

Tapley, BD. J. Ries, S. Bettapur, D. Chambers, M. Cheng, F. Condi, B. Gunter, Z. Kang, P. Nagel, R. Pastor, T. Pekker, S. Poole, and F. Wang (2005), GGM02- An improved Earth gravity model from GRACE, J. Geodesy, DOI 10.1007/s00190-005-0480-z. 